\title{
Diagnostic Test Accuracy of New Generation Tympanic Thermometry in Children under different cutoffs: A Systematic Review and Meta-analysis
}

\section{Dan Shi}

Hospital Affilited 5 to Nantong University (Taizhou People's Hoapital)

\section{Liyuan Zhang}

Hospital Affiliated 5 to Nantong Hospital (Taizhou People's Hospital)

\section{Haixia Li (D747254135@qq.com )}

Affiliated Hospital 5 to Nantong University (Taizhou People's Hospital) https://orcid.org/0000-0003$1336-2548$

\section{Research article}

Keywords: tympanic thermometry, pediatric, rectal, cutoff, Sensitivity, Specificity

Posted Date: March 27th, 2020

DOI: https://doi.org/10.21203/rs.2.21238/v2

License: (c) (i) This work is licensed under a Creative Commons Attribution 4.0 International License. Read Full License

Version of Record: A version of this preprint was published at BMC Pediatrics on May 12th, 2020. See the published version at https://doi.org/10.1186/s12887-020-02097-7. 


\section{Abstract}

Purposes: To identify and quantify studies reporting the diagnostic accuracy of the new generation of infrared tympanic thermometer (IRTT) in children and to compare the sensitivity and specificity of IRTT under different cutoffs and give the optimal cutoff.

Methods: Articles were derived from a systematic search in PubMed, Web of Science Core Collection, and Embase, and were assessed for internal validity by the Quality Assessment of Diagnostic Accuracy Studies-2 $\triangle Q U A D A S-\mathbb{Q}$. The figure of risk of bias was created by Review Manager 5.3 and data were synthesized by MetaDisc 1.4 .

Results: Nineteen diagnostic studies, involving 4,639 pediatric patients, were included. The cut-offs varied from $37.0^{\circ} \mathrm{C}$ to $38.0^{\circ} \mathrm{C}$ among these studies. The cut-off $37.8^{\circ} \mathrm{C}$ was with the highest sROC AUC (0.97) and Youden Index (0.83) and was deemed to be the optimal cutoff.

Conclusion: The optimal cutoff for infrared tympanic thermometers is $37.8^{\circ} \mathrm{C}$. New Generation Tympanic Thermometry is with high diagnostic accuracy in pediatric patients and can be an alternative for fever screening in children.

\section{Background}

Body temperature measurement is a routine in the management of sick children for both parents and healthcare providers[1, 2]. An accurate diagnosis of fever is crucial in clinical practice[3, 4] and an inaccurate one could lead to serious complications and improper medical decisions $[3,5]$. Core temperature is the gold standard for temperature measurement[3]. However, core temperature measurements, such as pulmonary artery and lower esophagus measurement, are invasive and requires specialized equipment, therefore, are unpractical for daily clinical practice[3, 6]. Ideally, body temperature measurement should be noninvasive, accurate, pain-free, cost-effective and time-efficient $[3,7,8]$.

Traditionally, non-invasive methods of body temperature measurement include rectal temperature, oral temperature and axillary temperature. Among these methods, rectal thermometry has been the most reliable for measuring body temperature in children and is considered clinically to be the best estimation of the core temperature[9]. However, it is time-consuming and requires certain level of practice $[5,10]$. Furthermore, it may cause emotional distress, and -although very rare- brings possible complications such as perforation or transmission of micro-organisms $[5,10]$. And therefore infants, health workers and parents more or less express reluctance to perform it[3].

The forehead skin thermometer (FST) and infrared tympanic thermometer (IRTT) are popular alternatives for the traditional measures. The FST uses a sensor probe to measure the amount of infrared heat produced by the temporal arteries[8]. The IRTT detects the radiation of tympanic membrane and the ear canal, which share the blood supply with the hypothalamus, the thermoregulatory center of the human body $[11,12]$. Both these two methods are safe, easy to use, comfortable and quick. But compared to the 
FST, the IRTT is more consistent with rectal temperature and is more convincing[3,8,13]. Using the aural temperature is less traumatic and allows a faster triage[14]囚but it has been debated for the low accuracy and reproducibility compared with other measurements[1, 14-18]. Over the past years, however, the IRTT have been developed and updated, and some older versions have been obsolete. The new generation IRTT used various brand-specific ways to enhance accuracy, for example, improvements of geometry and algorithms, a wider angle measurement, displaying temperature on multiple samples and equipping with a heat probe[11,19]. Synthesizing studies applying obsolete IRTT with the new ones is unreasonable and may underestimate the IRTT test accuracy. Furthermore, the cutoffs of the IRTT used in fever detection are diverse, and the optimal cut-off has no consensus. The cutoff means a temperature threshold that divides pediatric patients into fever and non-fever, and the diagnostic accuracy of IRTT various under different cutoffs $[3,13,20,21]$. It is inappropriate to synthesize studies applying different cutoffs and the results are unreliable.

The aims of this systematic review were (1) to identify and quantify studies reporting the diagnostic accuracy of the new generation of the IRTT in children (By new generation, we mean the IRTT that were still in production and on sale according to the official websites of the manufacturers as we started our study); (2) to compare the sensitivity and specificity under different cutoffs of the IRTT and give the optimal cutoff.

\section{Methods}

\section{Search strategies}

The conduct of this systematic review and meta-analysis was based on the Test Accuracy Working Group of the Cochrane Collaboration and the Preferred Reporting Items for Systematic Reviews and MetaAnalyses of Diagnostic Test Accuracy Studies statement (The PRISMA-DTA Statement) guidelines[22, 23]. A systematic literature search of multiple electronic databases (PubMed, Web of Science Core Collection, EMBASE) was conducted by two trained reviewers (D.S. and LY.Z.) independently from inception to February 2nd, 2019. The following search terms ((tympanic thermometer OR ear thermometer OR infrared thermometry OR ear thermometry OR tympanic scan OR tympanic temperature OR ear temperature OR infrared thermometer OR ear thermometer)) AND (pediatric OR child OR kid OR newborn OR baby OR infant OR toddler) in All Fields (PubMed, EMBASE) or Topic (Web of Science Core Collection) were used. The languages were restricted to English and species were restricted to humans. The bibliographies of included studies were also searched to identify additional studies.

\section{Study Selection}

Observational studies, detecting fever by aural and rectal thermometers, were deemed acceptable. Inclusion criterion included (1) studies recruiting pediatric subjects (age < 18 years), (2) diagnostic test accuracy studies, (3) studies detecting fever by new generation IRTT, and (4) studies using rectal thermometers as the reference standard. Exclusion criterion included (1) studies unrelated to the 
accuracy of IRTT, (2) reviews, proceedings paper, meeting abstract, letters, notes and editorial materials, and (3) studies lacking essential data.

Two reviewers (D.S. and LY.Z.) independently reviewed the titles and abstracts of these studies. Papers deemed to match the predefined inclusion criteria or without consensus were reviewed in full text. Disagreements were resolved through discussions and scientific consultations.

\section{Quality assessment and data extraction}

We adopted the Quality Assessment of Diagnostic Accuracy Studies-2 (QUADAS-2)[24] for quality assessment and used Review Manager 5.3 for creating the figures of risk of bias and applicability concerns[25]. Two independent reviewers (D.S. and LY.Z.) assessed the methodological quality of the included studies independently and disagreements were also resolved through discussions and scientific consultations.

The following data were extracted by two independent reviewers (D.S. and LY.Z) from the included studies: (1) descriptive aspects: primary author, year of publication, country, setting, age, types of tympanic thermometer and reference standard; (2) statistical aspects: the size, number of observations, the cut-off of tympanic thermometer, the True Positive (TP), the False Negative (FN), the False Positive (FP) and the True Negative (TN), sensitivity, specificity, positive predictive value (PPV) and negative predictive value (NPV).

\section{Statistical Analysis}

Meta-analyses of TP, FN, FP and TN were performed to compare the test accuracy between tympanic temperature and the gold standard (rectal temperature) by MetaDiSc 1.4[26]. Threshold analysis was conducted to evaluate the threshold effect[27]. The inconsistency index $\left(1^{2}\right)$ test was used to estimate heterogeneity between studies and $\mathrm{I}^{2}>75 \%$ was considered to be with high heterogeneity[28]. Data were synthesized by using the random-effects model which was recommended in pooled estimates of diagnostic meta-analyses[29]. The area under the curve (AUC), Youden index and index $Q^{\star}$ were used to measure test accuracy[30-32].

\section{Results}

\section{Selection process}

Initially, 611, 468 and 276 articles were retrieved from PubMed, Web of Science Core Collection and EMBASE respectively. Secondly, 332 duplicates were removed. Thirdly, the titles and abstracts of the remaining 1023 articles were examined and 975 articles were excluded for diverse reasons. Finally, 11 articles were selected after the full text review and 1 article[33] was added by reviewing references. The process and outcome of the literature selection are presented in detail in Figure 1.

\section{Risk of bias and applicability concerns in included studies}


Figure 2 and Figure 3 showed the risk of bias and applicability concerns in different domains. Among these 12 included articles, 4 had a high risk of bias on "flow and timing", "patient selection", "index test", and "reference standard", indicting the quality Methodological quality of included studies was moderate. Eight out of twelve studies had low applicability concerns in all domains and the applicability concerns was low.

\section{Characteristics of selected studies}

Twelve included studies were published from 2010 to 2018. All these studies applied the tympanic thermometer and set the rectal thermometer as reference standard. The descriptive and statistical characteristics of the 12 studies were presented in Table 1 and Table 2 respectively.

\section{Accuracy of Tympanic Thermometry in children under different cut-offs}

The 12 studies involved 4639 children. The cut-off points were various. Among the included articles, 7[5, $8,18,33-36]$ studies set the optimal cut-off and the other $5[3,13,14,20,21]$ studies analyzed the diagnostic test accuracy of tympanic thermometry under different cut-offs. The range of the cut-off point was from $37.0^{\circ} \mathrm{C}$ to $38.0^{\circ} \mathrm{C}$. Studies had data under same cut-off were synthesized.

\section{Accuracy under the cut-off of $37.0^{\circ} \mathrm{C}$}

There was only one study[3] reported diagnostic test accuracy under the cut-off $37.0^{\circ} \mathrm{C}$. In this study, for ear temperature $\left(37.0^{\circ} \mathrm{C}\right)$, sensitivity, specificity, PPV, and NPV were $0.89,0.84,0.91$, and 0.81 respectively

\section{Accuracy under the cut-off of $37.25^{\circ} \mathrm{C}$}

Only one study[34] gave the optimal cut-off $37.25^{\circ} \mathrm{C}$ and sensitivity, specificity, PPV, and NPV were 0.83 , $0.86,0.88$, and 0.80 respectively.

\section{Accuracy under the cut-off of $37.4^{\circ} \mathrm{C}$}

There was only one study[20] reported diagnostic test accuracy under the cut-off $37.4^{\circ} \mathrm{C}$. In this study, for ear temperature $\left(37.4^{\circ} \mathrm{C}\right)$, sensitivity, specificity, PPV, and NPV were $0.96,0.36,0.82$, and 0.73 respectively.

\section{Accuracy under the cut-off of $37.5^{\circ} \mathrm{C}$}

The cut-off $37.5^{\circ} \mathrm{C}$ was used in 2 studies[20,35] and a total of 390 pediatric patients were involved. The pooled sensitivity was $0.87(95 \% \mathrm{Cl} 0.79-0.92)$ and heterogeneity between the articles was high: $87.5 \%$ $\left(X^{2}=8.02, P<0.05\right)$. The pooled specificity was $0.95(95 \% \mathrm{Cl} 0.92-0.97)$ and heterogeneity between the articles was high: $97.9 \%\left(X^{2}=47.74, P<0.05\right)$.

\section{Accuracy under the cut-off of $37.6^{\circ} \mathrm{C}$}


The cut-off $37.6^{\circ} \mathrm{C}$ was used in 4 studies[3,13,20,21] and a total of 746 pediatric patients were involved. Spearman's correlation coefficient of sensitivity and specificity was $0.089(P=.638)$ and the ROC plane showed no curvilinear trend, suggesting that there was no heterogeneity from threshold effect. The pooled sensitivity was $0.76(95 \% \mathrm{Cl} 0.71-0.80)$ and heterogeneity between the articles was high: $94.3 \%$ $\left(X^{2}=53.04, P<0.05\right)$. The pooled specificity was 0.88 (95\% Cl 0.84-0.91) and heterogeneity between the articles was high: $92.9 \%\left(X^{2}=42.22, P<0.05\right)$ (Figure 5). The sROC AUC was $0.93(S E=0.02)$ while $Q^{*}$ value was $0.86(\mathrm{SE}=0.03)$.

\section{Accuracy under the cut-off of $37.7^{\circ} \mathrm{C}$}

There was only one study[20] reported diagnostic test accuracy under the cut-off $37.7^{\circ} \mathrm{C}$. In this study, for ear temperature $\left(37.7^{\circ} \mathrm{C}\right)$, sensitivity, specificity, PPV, and NPV were $0.91,0.60,0.87$, and 0.68 respectively.

\section{Accuracy under the cut-off of $37.8^{\circ} \mathrm{C}$}

The cut-off $37.8^{\circ} \mathrm{C}$ was used in 3 studies $[14,20,21]$ and a total of 1795 pediatric patients were involved. The threshold analysis $(r=\llbracket 0.050, P=.667)$ and the ROC plane (Figure) suggested that there was no heterogeneity from threshold effect. The pooled sensitivity was $0.92(95 \% \mathrm{Cl} 0.90-0.94)$ and heterogeneity between the articles was high: $80.1 \%\left(X^{2}=10.07, P<0.05\right)$. The pooled specificity was $0.91(95 \% \mathrm{Cl} 0.89$ $0.92)$ and heterogeneity between the articles was high: $94.5 \%\left(X^{2}=36.68, P<0.05\right)$ (Figure 6$)$. The sROC AUC was $0.97(\mathrm{SE}=0.02)$ while $Q *$ value was $0.91(\mathrm{SE}=0.03)$.

\section{Accuracy under the cut-off of $38.0^{\circ} \mathrm{C}$}

The cut-off $38.0^{\circ} \mathrm{C}$ was used in 7 studies $[5,8,13,14,18,33,36]$ and a total of 2783 pediatric patients were involved. The threshold analysis $(r=0.429, P=0.337)$ and the ROC plane suggested that there was no heterogeneity from threshold effect. The pooled sensitivity was $0.81(95 \% \mathrm{Cl} 0.79-0.84)$ and heterogeneity between the articles was high: $93.7 \%\left(X^{2}=94.51, P<0.05\right)$. The pooled specificity was 0.96 $(95 \% \mathrm{Cl} 0.95-0.97)$ and heterogeneity between the articles was high: $81.6 \%\left(X^{2}=32.56, P<0.05\right)$. The sROC AUC was $0.97(S E=0.01)$ while $Q *$ value was $0.92(S E=0.01)$.

The diagnostic test accuracy of the tympanic thermometry under different Cut-offs in the detection of pediatric fever is summarized in Table 3. The cut-off 37.8 is with the highest sROC AUC and Youden Index and is deemed to be the optimal cutoff.

\section{Discussion}

We conducted this study to assess the discriminant validity of the new generation IRTT for detecting pediatric fever determined by rectal thermometry and to find the optimal cutoff. Twelve studies, including 4639 children, were included. The results indicated that IRTT was a good alternative for rectal thermometry in pediatric patients, and the optimal cut-off of ear temperature for screening fever in 
children was $37.8^{\circ} \mathrm{C}$. Under this cut-off, pooled sensitivity was $0.92(95 \% \mathrm{Cl} 0.90-0.94)$, pooled specificity was $0.91(95 \% \mathrm{Cl} 0.89-0.92)$, sROC AUC was $0.97(\mathrm{SE}=0.02)$ and $\mathrm{Q} *$ value was $0.91(\mathrm{SE}=0.03)$.

One major strength of this study was that it estimated the test accuracy of new generation IRTT. Although the IRTT may provide a good alternative for traditional measurements, it has been debated for the low reproducibility. However, since the ear thermometer came out, it has been constantly updated and upgraded. Some techniques have been used to improve the test accuracy, such as the Braun Welch Allyn Pro 4000 Thermoscan, where a heating element in the sensor heats the probe tip to just below normal body temperature to avoid cooling the ear canal[19]. And the improvements of geometry and algorithms have been developed to ensure that the displayed result reflects the tympanic temperature accurately[11]. Hence, the newer versions of tympanic thermometers might meet the clinicians' requested improvements of repeatability in noninvasive temperature assessments. By new generation, we mean the IRTT that were still in production and on sale according to the official websites of the manufacturers as we started our study. We included the tympanic thermometers under use and excluded the outdated ones so that the results could provide a reference for current clinical practice.

Another strength of this study was that it estimated the test accuracy of new generation IRTT under different cutoffs. The synthesis of data under different cutoffs may underestimated the test accuracy of IRTT, because the diagnostic accuracy of IRTT varied under different cutoffs $[3,13,20,21]$. The cutoffs of IRTT ranged from $37.0^{\circ} \mathrm{C}$ to $38^{\circ} \mathrm{C}$ among these 12 included studies. After the synthesis of three studies, including 1795 children, we found the optimal cut-off of tympanic thermometry is $37.8^{\circ} \mathrm{C}$. And under this cutoff, the pooled sensitivity was 0.92 ( $95 \% \mathrm{Cl} 0.90-0.94)$, pooled specificity was 0.91 (95\% $\mathrm{Cl} 0.89-0.92)$, sROC AUC was $0.97(\mathrm{SE}=0.02)$ and $Q *$ value was $0.91(\mathrm{SE}=0.03)$.

The diagnostic accuracy in this study under the optimal cutoff was far higher than a former systematic review[27], in which pooled sensitivity was 0.70 (95\% $\mathrm{Cl} 0.68-0.72)$, pooled specificity was $0.86(95 \% \mathrm{Cl}$ $0.85-0.88$ ), sROC AUC was 0.94 , and $Q^{*}$ value was 0.87 . Excluding articles applying obsolete tympanic thermometers and analyzing diagnostic test accuracy under different cut-offs may be the major reasons for this gap.

The 12 included studies are with high homogeneity, because they have the same study type, study population, reference standard and et al. And data were synthesized by using the random-effects model. What should be underlined is that the heterogeneity between the articles is very high, from $81.6 \%$ to $94.5 \%$. The study population of included studies are all children, who age from 0 to 18 -year-old. But the age groups are various, for example, Duru et al[35] admitted neonates whose mean age is $6.63 \pm 6.98$ days, while Allegaert et al[5] enrolled children with a median age of 3.2 years (range 0.02years to 17 years). The variation of age groups may be the major contribution to the high heterogeneity and further studies focusing on different age groups are needed.

Although the results of our study can provide an important reference for subsequent researches and clinical applications, there are two limitations in our present study. We performed different sub-group meta-analyses based on the different cut-offs used. Unfortunately, in many of these analyses a limited 
number of studies are included. We concluded that $37.8^{\circ} \mathrm{C}$ was the optimal cut-off just based on three studies, which seemed unconvincing. But considering that 1795 subjects were included for analysis under the cut-off $37.8^{\circ} \mathrm{C}$, the conclusion was much more convincing.

According to the findings, ear canal temperature can be confidently implemented as a screening measure in the pediatric fever detection. This application of IRTT would effectively decrease the number of children who require the rectal temperature method for fever detection[7]. However, there are some situations, such as uncertain diagnosis[7], during exercise[37, 38], change of environmental temperatures[39], that tympanic temperature should not be used as a surrogate for rectal temperature.

\section{Conclusion}

Tympanic thermometry has a high diagnostic accuracy and is a good alternative for temperature screening in pediatric patients. The optimal cut-off of ear temperature for screening fever in children is $37.8^{\circ} \mathrm{C}$.

\section{List Of Abbreviations}

IRTT: infrared tympanic thermometer

FP: the False Positive

FN: the False Negative

NPV: negative predictive value

PPV: positive predictive value

The PRISMA-DTA Statement: the Preferred Reporting Items for Systematic Reviews and Meta-Analyses of Diagnostic Test Accuracy Studies

QUADAS-2: the Quality Assessment of Diagnostic Accuracy Studies-2

TP: the True Positive

TN: the True Negative

\section{Declarations}

\section{Ethics approval and consent to participate}

Not applicable.

\section{Consent for publication}


Not applicable.

\section{Availability of data and materials}

Not applicable.

\section{Competing interests}

The authors declare that they have no competing interests.

\section{Funding}

There is no funding source.

\section{Authors' contributions}

S.D. took part in the study design, literature research, assessments of research, data analysis and manuscript preparation. LY.Z. took part in the study design, literature research and assessments of research. HX.L. was the guarantor of integrity of entire study and led the study design.All authors read and approved the final manuscript.

\section{Acknowledgements}

Not applicable.

\section{References}

1. Dogan HH, Sezer RG, Kirkgoz T, Bozaykut A. Comparison of Axillary and Tympanic Temperature Measurements in Children Diagnosed with Acute Otitis Media. Int J Pediatr 2016, 2016:1729218.

2. Barton SJ, Gaffney R, Chase T, Rayens MK, Piyabanditkul L. Pediatric temperature measurement and child/parent/nurse preference using three temperature measurement instruments. J PEDIATR NURS 2003, 18(5):314-320.

3. Chatproedprai S, Heamawatanachai K, Tempark T, Wananukul S. A Comparative Study of 3 Different Methods of Temperature Measurement in Children. J Med Assoc Thai 2016, 99(2):142-149.

4. Davis T. NICE guideline: feverish illness in children-assessment and initial management in children younger than 5 years. Arch Dis Child Educ Pract Ed 2013, 98:232-235.

5. Allegaert K, Casteels K, van Gorp I, Bogaert G. Tympanic, infrared skin, and temporal artery scan thermometers compared with rectal measurement in children: a real-life assessment. Curr Ther Res Clin Exp 2014, 76:34-38.

6. Abdulkadir MB, Johnson B. A comparative study of rectal tympanic and axillary thermometry in febrile children under 5 years of age in Nigeria. Paediatr Int Child Health 2013, 33(3):165-169. 
7. Chiappini E, Principi N, Longhi R, Tovo PA, Becherucci P, Bonsignori F, Esposito S, Festini F, Galli L, Lucchesi $\mathrm{B}$, et al. Management of fever in children: summary of the Italian Pediatric Society guidelines. CLIN THER 2009, 31(8):1826-1843.

8. Paes BF, Vermeulen K, Brohet RM, van der Ploeg T, de Winter JP. Accuracy of tympanic and infrared skin thermometers in children. ARCH DIS CHILD 2010, 95(12):974-978.

9. Dinarello CA, Wolff SM. Principles and Practice of Infectious Diseases, 3 edn. New York: Churchill Livingstone; 1990.

10. Apa H, Gozmen S, Bayram N, Catkoglu A, Devrim F, Karaarslan U, Gunay I, Unal N, Devrim I. Clinical accuracy of tympanic thermometer and noncontact infrared skin thermometer in pediatric practice: an alternative for axillary digital thermometer. PEDIATR EMERG CARE 2013, 29(9):992-997.

11. Aadal L, Fog L, Pedersen AR. Tympanic ear thermometer assessment of body temperature among patients with cognitive disturbances. An acceptable and ethically desirable alternative? SCAND J CARING SCI 2016, 30(4):766-773.

12. Denis Leduc SW, Val-d'Or. Community Paediatrics Committee. Temperature Measurements in Paediatrics. Ontario: Canadian Paediatric Society, 2007.

13. Teller J, Ragazzi M, Simonetti GD, Lava SA. Accuracy of tympanic and forehead thermometers in private paediatric practice. ACTA PAEDIATR 2014, 103(2):e80-e83.

14. Mogensen CB, Wittenhoff L, Fruerhoj G, Hansen S. Forehead or ear temperature measurement cannot replace rectal measurements, except for screening purposes. BMC PEDIATR 2018, 18(1):15.

15. Robinson JL, Seal RF, Spady DW, Joffres MR. Comparison of esophageal, rectal, axillary, bladder, tympanic, and pulmonary artery temperatures in children. J Pediatr 1998, 133(4):553-556.

16. Hamilton PA, Marcos LS, Secic M. Performance of infrared ear and forehead thermometers: a comparative study in 205 febrile and afebrile children. J CLIN NURS 2013, 22(17-18):2509-2518.

17. Akinyinka OO, Omokhodion SI, Olawuyi JF, Olumese PE, Brown BJ. Tympanic thermometry in Nigerian children. Ann Trop Paediatr 2001, 21(2):169-174.

18. Sund-Levander M, Grodzinsky E. Time for a change to assess and evaluate body temperature in clinical practice. INT J NURS PRACT 2009, 15(4):241-249.

19. Haugan B, Langerud AK, Kalvoy H, Froslie KF, Riise E, Kapstad H. Can we trust the new generation of infrared tympanic thermometers in clinical practice? J CLIN NURS 2013, 22(5-6):698-709.

20. Paramita T, Karyanti MR, Soedjatmiko, Hendarto A, Suyoko D, Latief A. A comparison of axillary and tympanic membrane to rectal temperatures in children. PAEDIATRICA INDONESIANA 2017, 57(1):4751.

21. Edelu BO, Ojinnaka NC, Ikefuna AN. Fever detection in under 5 children in a tertiary health facility using the infrared tympanic thermometer in the oral mode. ITAL J PEDIATR 2011, 37:8.

22. Leeflang MM, Deeks JJ, Gatsonis C, Bossuyt PM. Systematic reviews of diagnostic test accuracy. ANN INTERN MED 2008, 149(12):889-897. 
23. Mclnnes MDF, Moher D, Thombs BD, McGrath TA, Bossuyt PM, Clifford T, Cohen JF, Deeks JJ, Gatsonis C, Hooft L, et al. Preferred Reporting Items for a Systematic Review and Meta-analysis of Diagnostic Test Accuracy Studies. JAMA 2018, 319(4):388.

24. Greiner M, Pfeiffer D, Smith RD. Principles and practical application of the receiver-operating characteristic analysis for diagnostic tests. PREV VET MED 2000, 45(1-2):23-41.

25. Review Manager (RevMan) [Computer Program]. Version 5.3. Copenhagen,Denmark: The Nordic Cochrane Centre, The Cochrane Collaboraiton, 2014.

26. Zamora J, Abraira V, Muriel A, Khan K, Coomarasamy A. Meta-DiSc: a software for meta-analysis of test accuracy data. BMC MED RES METHODOL 2006, 6:31.

27. Zhen C, Xia Z, Ya Jun Z, Long L, Jian S, Gui Ju C, Long L. Accuracy of Infrared Tympanic Thermometry Used in the Diagnosis of Fever in Children. CLIN PEDIATR 2014, 54(2):114-126.

28. Higgins JP, Thompson SG. Quantifying heterogeneity in a meta-analysis. STAT MED 2002, 21(11):1539-1558.

29. Cochrane handbook for systematic reviews of diagnostic test accuracy. 2013. The Cochrane Collaboration. http://srdta.cochrane.org/. Accessed February 26th, 2019.

30. Samawi HM, Yin J, Rochani H, Panchal V. Notes on the overlap measure as an alternative to the Youden index: How are they related? STAT MED 2017, 36(26):4230-4240.

31. Walter SD. Properties of the summary receiver operating characteristic (SROC) curve for diagnostic test data. STAT MED 2002, 21(9):1237-1256.

32. Shi D, Chen X, Li Z. Diagnostic test accuracy of the Montreal Cognitive Assessment in the detection of post-stroke cognitive impairment under different stages and cutoffs: a systematic review and meta-analysis. Neurol Sci 2018, 39(4):705-716.

33. Batra P, Goyal S. Comparison of Rectal, Axillary, Tympanic, and Temporal Artery Thermometry in the Pediatric Emergency Room. PEDIATR EMERG CARE 2013, 29(1):63-66.

34. Acikgoz M, Guzel A, Mura N, Karli A, Sezgin U. Reliability of the Infrared and Chemical Dot Temperature Measurement Methods in the Children Admitted in the Pediatric Emergency Unit: A Prospective Study. KUWAIT MED J 2016, 48(2):105-110.

35. Duru CO, Akinbami FO, Orimadegun AE. A comparison of tympanic and rectal temperatures in term Nigerian neonates. BMC PEDIATR 2012, 12:86.

36. Oyakhirome S, Profanter K, Kremsner PG. Assessment of fever in African children: implication for malaria trials. AM J TROP MED HYG 2010, 82(2):215-218.

37. Huggins R, Glaviano N, Negishi N, Casa DJ, Hertel J. Comparison of Rectal and Aural Core Body Temperature Thermometry in Hyperthermic, Exercising Individuals: A Meta-Analysis. J Athl Train. 2012;47(3):329-338.

38. Casa DJ, Becker SM, Ganio MS, et al. Validity of Devices That Assess Body Temperature During Outdoor Exercise in the Heat. J Athl Train. 2007;42(3):333-342. 
39. Purssell E, While A, Coomber B. Tympanic thermometry - normal temperature and reliability. Paediatr Nurs. 2009; 21: 40-43.

\section{Tables}

Table 1 Descriptive characteristics of including studies

\begin{tabular}{|c|c|c|c|c|c|c|}
\hline Studies & Year & Country & Setting & Age & $\begin{array}{c}\text { Tympanic } \\
\text { thermometer }\end{array}$ & $\begin{array}{c}\text { Reference } \\
\text { standard }\end{array}$ \\
\hline $\begin{array}{l}\text { Mogensen et } \\
\mathrm{al}^{[13]}\end{array}$ & 2018 & Denmark & $\begin{array}{l}\text { pediatric emergency } \\
\text { department }\end{array}$ & $0-18 y$ & $\begin{array}{l}\text { Braun Welch } \\
\text { Allyn Pro } \\
4000\end{array}$ & Rectal \\
\hline $\begin{array}{l}\text { Paramita et } \\
\mathrm{al}^{[33]}\end{array}$ & 2017 & Indonesia & $\begin{array}{l}\text { Pediatric outpatient clinic/ } \\
\text { pediatric emergency } \\
\text { department/ inpatient } \\
\text { pediatrics ward }\end{array}$ & $6 m-5 y$ & $\begin{array}{l}\text { Thermoscan } \\
\text { OMRON } \\
\text { Gentle Temp } \\
510\end{array}$ & Rectal \\
\hline $\begin{array}{l}\text { Chatproedprai } \\
\text { et al }^{[3]}\end{array}$ & 2016 & Thailand & Pediatric outpatient clinic & $0-2 y$ & $\begin{array}{l}\text { Microlife } \\
\text { IR1DE1-1 }\end{array}$ & Rectal \\
\hline $\begin{array}{l}\text { Acikgoz et } \\
\mathrm{al}^{[30]}\end{array}$ & 2016 & Turkey & $\begin{array}{l}\text { pediatric emergency } \\
\text { department }\end{array}$ & $3 \mathrm{~m}-3 y$ & Genius $^{\mathrm{TM}} 2$ & Rectal \\
\hline $\begin{array}{l}\text { Allegaert et } \\
\mathrm{al}^{[5]}\end{array}$ & 2014 & Belgium & Pediatric wards & $2 m-17 y$ & Genius $^{\mathrm{TM}} 2$ & Rectal \\
\hline $\begin{array}{l}\text { Teller et } \\
\mathrm{al}^{[34]}\end{array}$ & 2014 & Swizerland & Pediatric practice & $1 \mathrm{~m}-2 \mathrm{y}$ & $\begin{array}{l}\text { Braun } \\
\text { Thermoscan } \\
6022^{\mathrm{TM}}\end{array}$ & Rectal \\
\hline $\begin{array}{l}\text { Hamilton et } \\
\mathrm{al}^{[15]}\end{array}$ & 2014 & America & $\begin{array}{l}\text { The emergency department } \\
\text { and the overflow patient } \\
\text { treatment areas }\end{array}$ & $0-18 y$ & $\begin{array}{l}\text { Braun Welch } \\
\text { Allyn Pro } \\
4000 \\
\text { Thermoscan }\end{array}$ & Rectal \\
\hline $\begin{array}{l}\text { Batra et } \\
\text { al }^{[29]}\end{array}$ & 2013 & India & The pediatric emergency room & $2-12 y$ & $\begin{array}{l}\text { Equinox } \\
\text { infrared ear } \\
\text { thermometer } \\
\text { (EQ ET 99) }\end{array}$ & Rectal \\
\hline Duru et $\mathrm{al}^{[31]}$. & 2012 & Nigeria & The neonatal wards & $6.63 \pm 6.98 d$ & $\begin{array}{c}\text { Braun IRT } \\
4520 \\
\text { Thermoscan }\end{array}$ & Rectal \\
\hline Edelu et $\mathrm{al}^{[35]}$ & 2011 & Nigeria & $\begin{array}{l}\text { Pediatric outpatient clinic/ } \\
\text { pediatric emergency } \\
\text { department }\end{array}$ & $0-5 y$ & $\begin{array}{c}\text { OMRON } \\
\text { instant ear } \\
\text { thermometer } \\
\text { model MC- } \\
509 \mathrm{~N}\end{array}$ & Rectal \\
\hline Paes et al ${ }^{[8]}$ & 2010 & Netherlands & The pediatric ward & $0-18 y$ & $\begin{array}{l}\text { The FirstTemp } \\
\text { Genius } \\
\text { tympanic } \\
\text { thermometer } \\
3000 \mathrm{~A}\end{array}$ & Rectal \\
\hline $\begin{array}{l}\text { Oyakhirome et } \\
\mathrm{al}^{[32]}\end{array}$ & 2010 & Gabon & The outpatient department & $0-10 y$ & $\begin{array}{l}\text { Braun } 6022 \\
\text { Thermoscan }\end{array}$ & Rectal \\
\hline
\end{tabular}

\section{Table 2 Statistical characteristics of including studies}




\begin{tabular}{|c|c|c|c|c|c|c|c|c|c|c|}
\hline Studies & Sample & Cut-off & TP & FP & FN & TN & $\mathrm{Se}$ & $\mathrm{Sp}$ & PPV & NPV \\
\hline \multirow[t]{2}{*}{ Mogensen et al ${ }^{[13]}$} & 995 & 37.8 & 372 & 76 & 20 & 527 & 95 & 87 & 83 & 96 \\
\hline & & 38.0 & 350 & 36 & 43 & 566 & 89 & 94 & 91 & 93 \\
\hline \multirow[t]{5}{*}{ Paramita et al ${ }^{[33]}$} & 90 & 37.4 & 65 & 14 & 3 & 8 & 96 & 36 & 82 & 73 \\
\hline & & 37.5 & 64 & 11 & 4 & 11 & 94 & 50 & 85 & 73 \\
\hline & & 37.6 & 63 & 11 & 5 & 11 & 93 & 50 & 85 & 69 \\
\hline & & 37.7 & 62 & 9 & 6 & 13 & 91 & 60 & 87 & 68 \\
\hline & & 37.8 & 60 & 6 & 8 & 16 & 88 & 73 & 91 & 66 \\
\hline \multirow[t]{2}{*}{ Chatproedprai et al ${ }^{[3]}$} & 312 & 37.0 & 181 & 17 & 22 & 92 & 89 & 84 & 91 & 81 \\
\hline & & 37.6 & 126 & 1 & 77 & 108 & 62 & 99 & 99 & 58 \\
\hline Acikgoz et al ${ }^{[30]}$ & 354 & 37.25 & 163 & 22 & 33 & 136 & 83 & 86 & 88 & 80 \\
\hline Allegaert et al ${ }^{[5]}$ & 294 & 38.0 & 5 & 0 & 17 & 272 & 22 & 100 & 100 & 94 \\
\hline \multirow[t]{2}{*}{ Teller et al ${ }^{[34]}$} & 254 & 38.0 & 72 & 4 & 28 & 150 & 72 & 97 & 95 & 84 \\
\hline & & 37.6 & 93 & 25 & 7 & 129 & 93 & 84 & 79 & 95 \\
\hline Hamilton et al ${ }^{[15]}$ & 205 & 38.0 & 87 & 8 & 6 & 104 & 94 & 93 & 92 & 95 \\
\hline Batra et al ${ }^{[29]}$ & 100 & 38.0 & 49 & 1 & 1 & 49 & 98 & 98 & 98 & 98 \\
\hline Duru et $\mathrm{al}^{[31]}$ & 300 & 37.5 & 34 & 3 & 11 & 252 & 76 & 99 & 93 & 97 \\
\hline \multirow[t]{2}{*}{ Edelu et al ${ }^{[35]}$} & 710 & 37.8 & 316 & 10 & 39 & 345 & 89 & 97 & 97 & 90 \\
\hline & 90 & 37.6 & 33 & 4 & 12 & 41 & 73 & 91 & 89 & 77 \\
\hline Paes et al ${ }^{[8]}$ & 100 & 38.0 & 20 & 2 & 5 & 73 & 80 & 97 & 91 & 94 \\
\hline Oyakhirome et al ${ }^{[32]}$ & 835 & 38.0 & 337 & 19 & 112 & 357 & 75 & 95 & 94 & 76 \\
\hline
\end{tabular}

Table 3 Accuracy of tympanic thermometry under different cutoffs in children 


\begin{tabular}{cccccc}
\hline Cut-off $\left({ }^{\circ} \mathrm{C}\right)$ & $\mathrm{N}$ & Sen & Sp & Youden Index & SROC-AUC \\
\hline 37.0 & 312 & 89 & 84 & 0.73 & $\mathrm{~N}$ \\
37.25 & 354 & 83 & 86 & 0.69 & $\mathrm{~N}$ \\
37.4 & 90 & 96 & 36 & 0.32 & $\mathrm{~N}$ \\
37.5 & 390 & 87 & 95 & 0.82 & $\mathrm{~N}$ \\
37.6 & 746 & 76 & 88 & 0.64 & 0.93 \\
37.7 & 90 & 91 & 60 & 0.51 & $\mathrm{~N}$ \\
37.8 & 1795 & 92 & 91 & 0.83 & 0.97 \\
38.0 & 2578 & 80 & 96 & 0.76 & 0.97 \\
\hline
\end{tabular}

Figures 


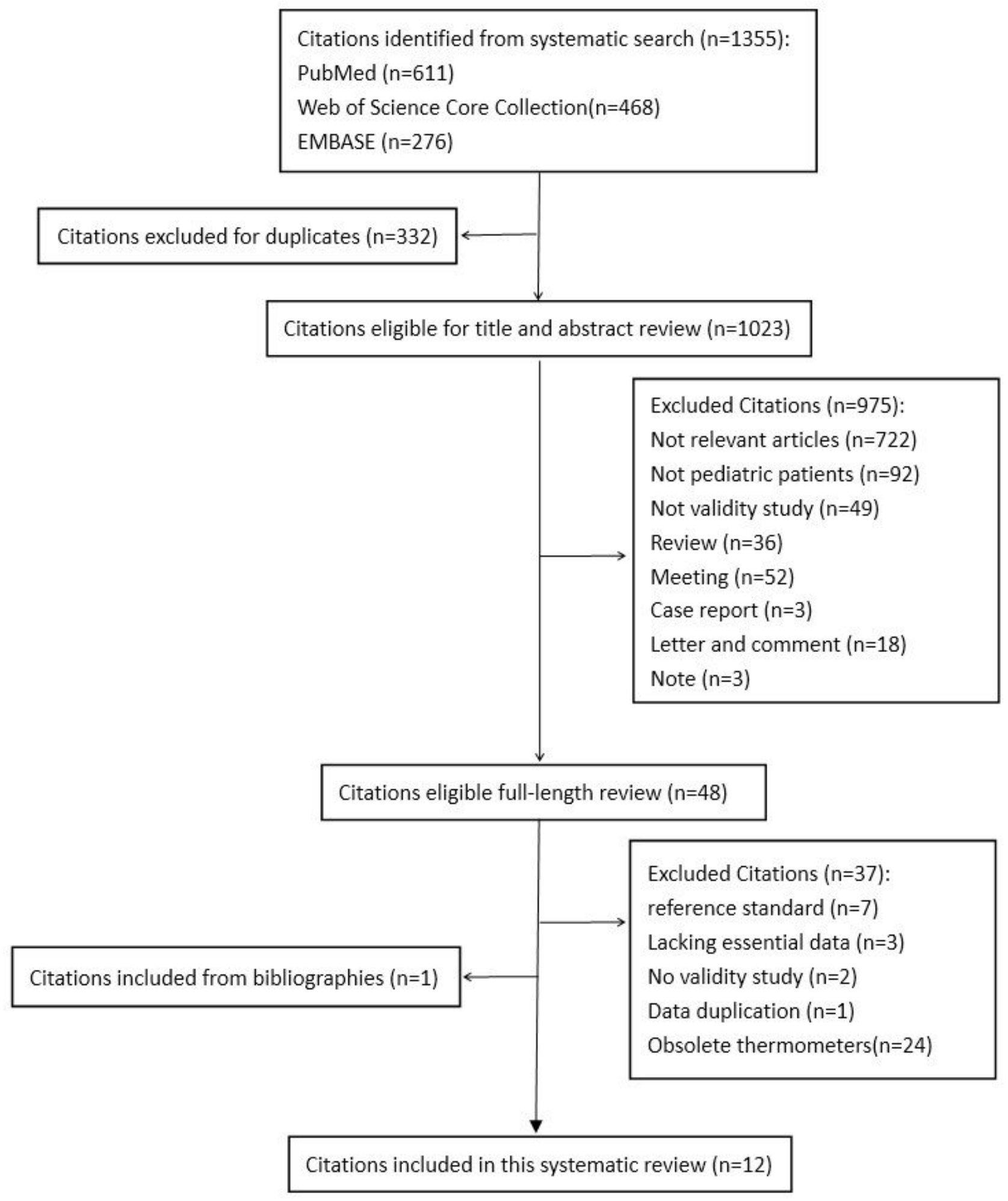

\section{Figure 1}

Study flow diagram of study selection process 


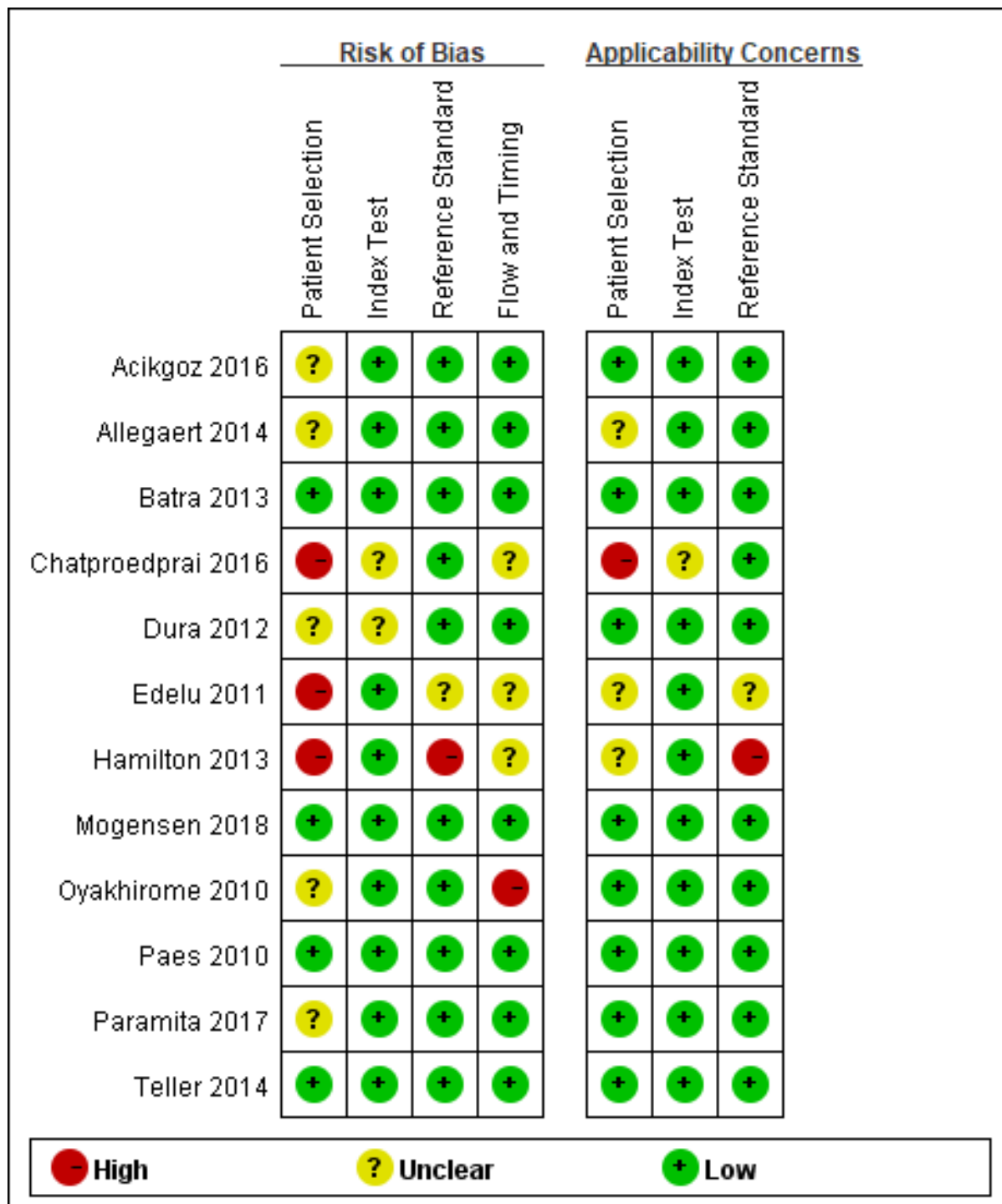

Figure 2

Outcomes of quality assessment of each included studies (by QUADAS-2)

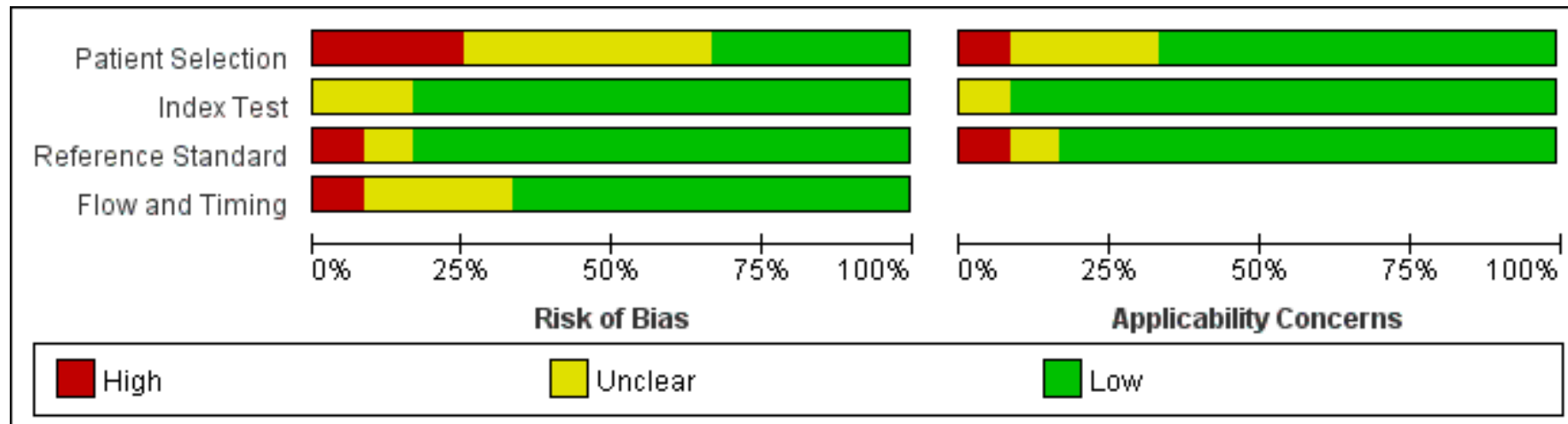

Figure 3 
Overall quality assessment of included studies (by QUADAS-2): proportion of studies with low, unclear, and high risk of bias (left), and proportion of studies with low, unclear, and high concerns regarding applicability (right)
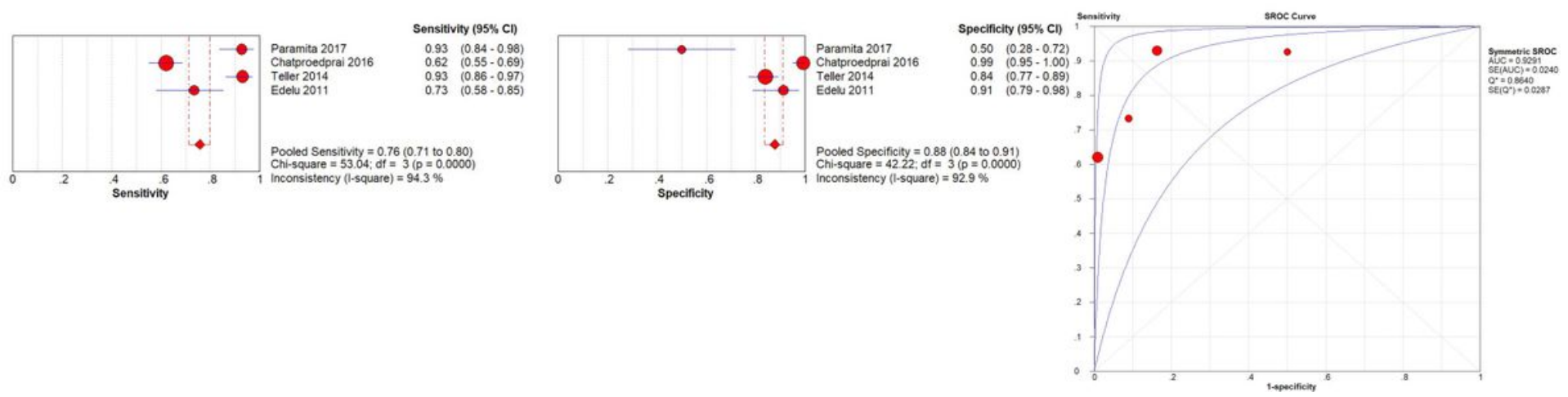

\section{Figure 4}

Figure 4-1 The pooled sensitivity of tympanic Thermometry in Children under cut-off $37.6^{\circ} \mathrm{C}$ Figure $4-2$ The pooled specificity of tympanic Thermometry in Children under cut-off $37.6^{\circ} \mathrm{C}$ Figure $4-3$ The sROC Curve of tympanic Thermometry in Children under cut-off $37.6^{\circ} \mathrm{C}$
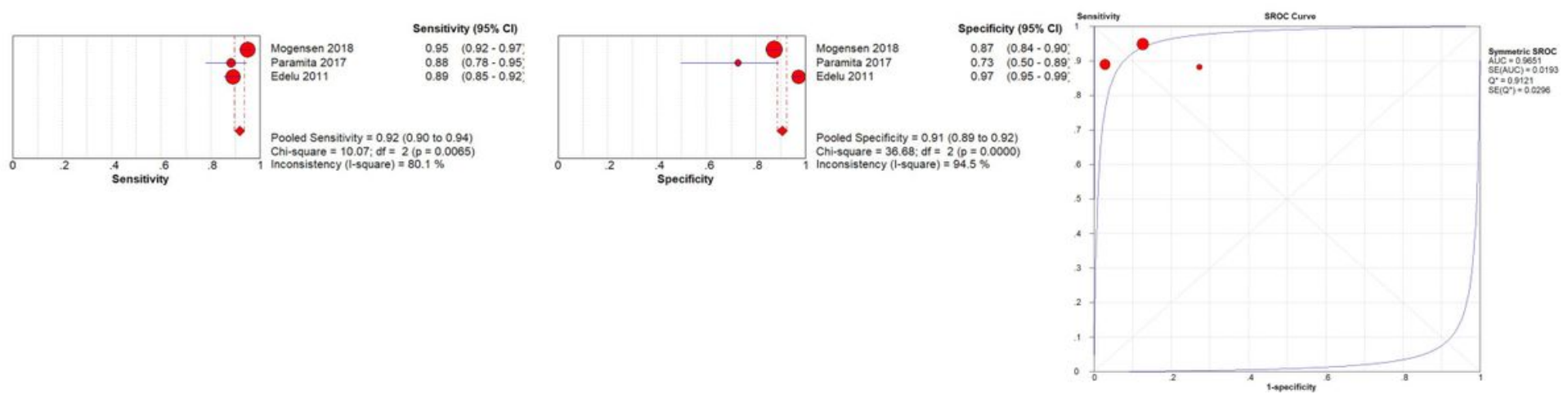

\section{Figure 5}

Figure 5-1 The pooled sensitivity of tympanic Thermometry in Children under cut-off $37.8^{\circ} \mathrm{C}$ Figure $5-2$ The pooled specificity of tympanic Thermometry in Children under cut-off $37.8^{\circ} \mathrm{C}$ Figure $5-3 \mathrm{The}$ sROC Curve of tympanic Thermometry in Children under cut-off $37.8^{\circ} \mathrm{C}$
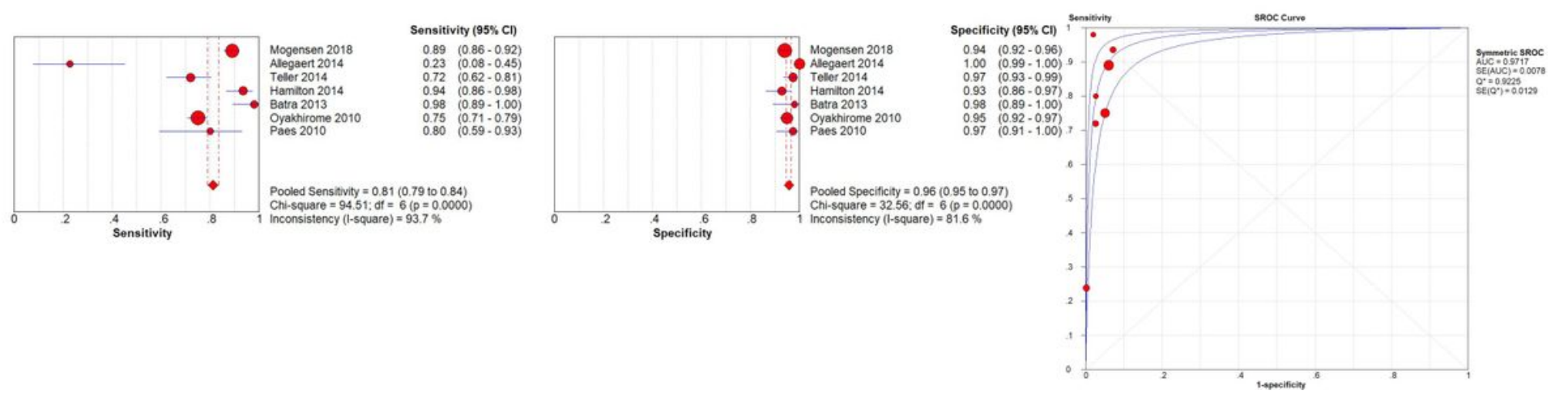

\section{Figure 6}


Figure 6-1 The pooled sensitivity of tympanic Thermometry in Children under cut-off $38.0^{\circ} \mathrm{C}$ Figure $6-2$ The pooled specificity of tympanic Thermometry in Children under cut-off $38.0^{\circ} \mathrm{C}$ Figure $6-3 \mathrm{The}$ sROC Curve of tympanic Thermometry in Children under cut-off 38.0

\section{Supplementary Files}

This is a list of supplementary files associated with this preprint. Click to download.

- PRISMA2009checklist.doc 